\title{
STATCOM Power Frequency Model with VSC Charging Dynamics and its Application in the Power System Stability Analysis
}

\author{
Y. Ni L. Snider \\ Electrical and Electronic Department \\ The University of Hong Kong \\ Hong Kong
}

\begin{abstract}
In this paper the STATCOM power frequency model is derived with voltage source converter charging dynamics. The main control and supplementary control are then added for voltage regulation and damping power oscillation. The integrated STATCOM system model is used in power system transient stability analysis. Computer program is developed based on Power System Toolbox of MATLAB. Computer test results show clearly the effects of the STATCOM on system dynamic behavior and transfer limit.
\end{abstract}

\section{Introduction}

The Static Synchronous Compensator (STATCOM) previously referred to as the STATCON, ASVC or ASVG, resembles in many respects a rotating machine used for reactive power compensation. The STATCOM is based on a voltage source converter (VSC) with only small capacitors on the dc side. The principles of a STATCOM can be found in $[1,2]$. In [3] the largest 100MVAI STATCOM project is introduced which utilizes the stateof-the-art technology. Another large STATCOM project was reported in [4]. In [5] further feasibility studies of STATCOM application are conducted which show the great potential of making use of the STATCOM to enhance system transfer limit and controllability.

Most of the papers on STATCOM use EMTP (or EMTDC ) or hardware model to study its performance[6,7]. The test systems have to be quite small. In [8], a versatile approximate model of FACTS controllers for large scale power system transient stability analysis is suggested. It is highly desired to derive a STA TCOM power frequency model from its circuit diagram and real waveforms and interface it with traditional power system dynamic analysis programs to study the effects of STATCOM on the large scale power system dynamic behavior with satisfied accuracy.

In this paper a STATCOM power frequency model is derived with VSC charging dynamics. The main control and supplementary control are then added for voltage regulation and damping power oscillation. The integrated STATCOM model is used in power system transient stability analysis. Computer program is developed based on the Power System Toolbox[9] of MATLAB. The computer test results show clearly the effects of a
STATCOM on the system dynamic behavior and transfer limit.

\section{Derivation of STATCOM system model}

\subsection{STATCOM power frequency model}

A 6-pulse GTO thyristor bridge based STATCOM circuit diagram is shown in Figure 1 for deriving STATCOM model. The results can be extended for the multi-bridge STATCOM with no difficulty. The following assumptions are made in model derivation:

* The ac system is a 3 -phase symmetric voltage source.

* The transformer connecting the GTO thyristor bridge to the ac system is modeled as a symmetric shortcircuit inductance Is.

* The GTO thyristor bridge is ideal, i.e. when a valve turns on, its voltage drop is zero; and when it turns off, its current is zero.

* The STATCOM is lossless.

The steady state phasor diagram of STATCOM as a capacitive or inductive load of a power system is given in Figure 2. It is clear that at the steady state only reactive power is exchanged between the STATCOM and the ac system. When the ac system voltage $E$ is greater than the STATCOM internal bus voltage $V s$, it operates as an inductive load and otherwise a capacitive load.

The steady state STATCOM current and voltage waveforms derived from an EMTP simulation are shown in Figure 3.

Now we start to derive the power frequency model for STATCOM with VSC charging dynamics. In Figure 1 the neutral of ac system is denoted as o which is taken as the voltage reference. The capacitor voltage is $V d$, and the system voltage $e_{a}=\sqrt{2} E_{\Phi} \sin \omega t$. It can be proved that the magnitude of fundamental wave of STATCOM internal bus line to neutral voltage is (in MKS unit):

$$
v_{s a, 1}=v_{s a n, 1}=\sqrt{2} V_{s}=\frac{2 V_{s}}{\pi}
$$

which is determined by the total voltage of capacitors $V d$. In equation (1), subscript $\Phi$ means phase or line to neutral variables. In the dynamics, if the phase angle of $\dot{V}$ is $\theta$ and the phase angle of $\dot{V}_{s}$ is controlled as $(\theta-\varphi)$, where $\varphi>0$ means charging of the capacitors to increase its voltage 
and reactive power output, $\varphi<0$ means discharging of the capacitors to decrease its voltage and reactive power output. According to the assumption of lossless STATCOM, we know the input ac power

$$
P_{a r}=\frac{3 E_{\Phi} V_{\oplus}}{\omega L_{s}} \sin \varphi=\frac{3 E_{\Phi} V_{s}}{X_{s}} \sin \varphi
$$

should be equal to the power absorbed by capacitors, i.e.

$$
P_{d}=V_{d} I_{d}=V_{d} C \frac{d V_{d}}{d t}
$$

In equation (3), Id and $V d$ are the average charging current and capacitor voltage respectively with harmonics neglected. Connecting equations (2) and (3), substitute $V_{d}$ by equation (1), we have:

or

$$
\frac{3 E_{\Phi} V_{s \Phi}}{X_{s}} \sin \varphi=\left(\frac{\sqrt{2}}{2} \pi\right)^{2} V_{s \Phi} C \frac{d V_{s \Phi}}{d t}
$$

$$
\frac{d V_{s \Phi}}{d t}=\frac{6 \omega_{0}}{\pi^{2} X_{s} B_{c}} E_{\Phi} \sin \varphi=K_{s} E_{\Phi} \sin \varphi
$$

Equation (4) reflects the capacitor charging dynamics when $\varphi \neq 0$.

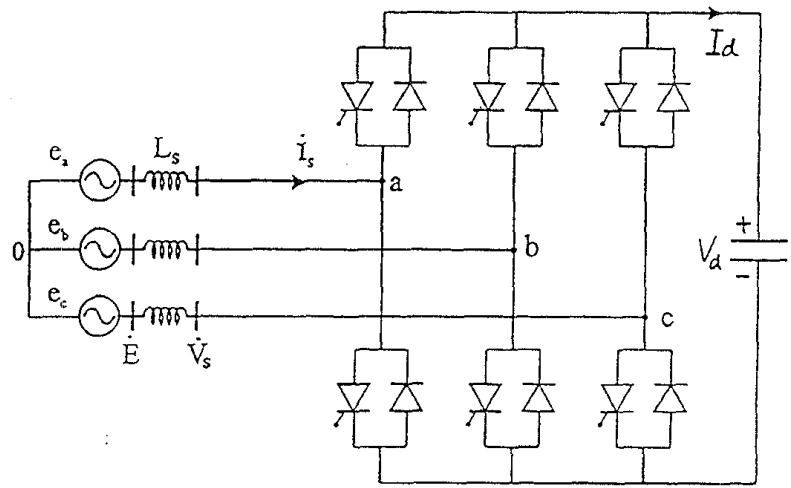

Figure 1: Circuit diagram of 6-pulse STATCOM

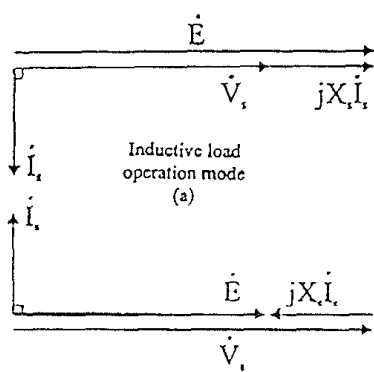

Capacitive load operation mode

Figure 2 Phasor Diagram of Statcom

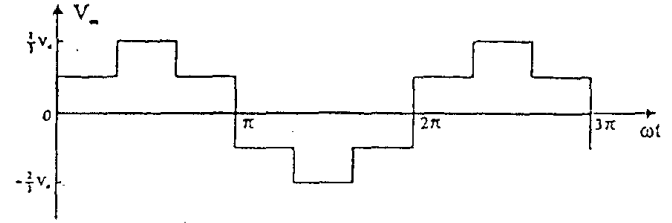

(a) Internal bus phase voltage

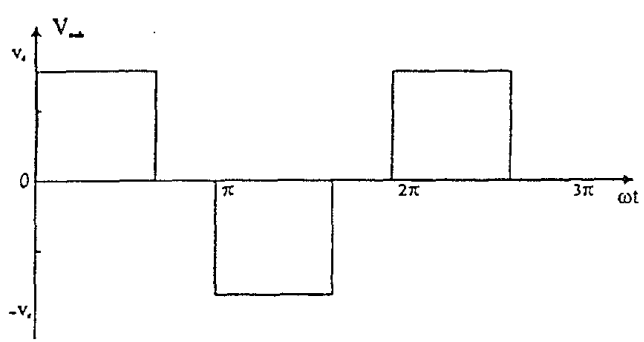

(b) Intemal bus phase-to-phase voltage

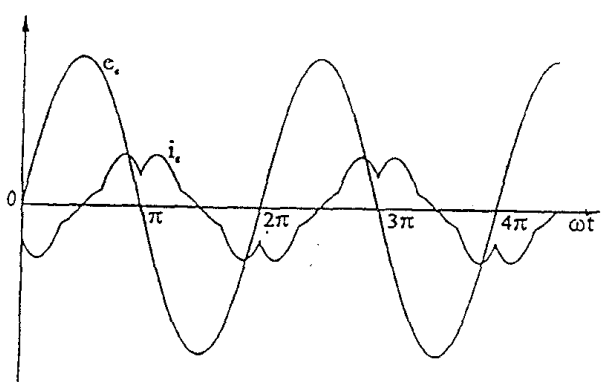

(c) Inductive load current

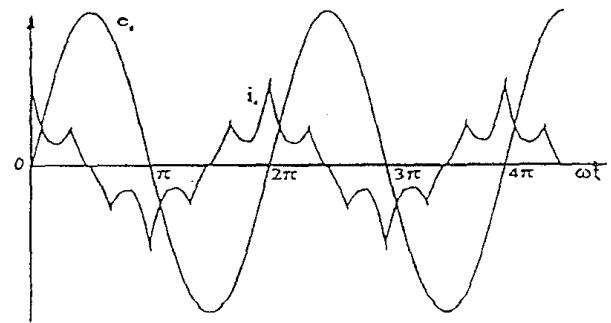

(d) Capacitive load current

Figure 3:STATCOM currents and internal bus voltages 
If we select base values of the per unit system properly as follows:

$$
\begin{aligned}
& S_{d B}=S_{a c B}, \quad V_{d B}=\sqrt{2} V_{\Phi B} \\
& I_{d B}=\frac{S_{d B}}{V_{d B}}=\frac{S_{a c B}}{3 V_{\Phi B}} \times \frac{3}{\sqrt{2}}=\frac{3}{\sqrt{2}} I_{a c B} \\
& X_{B}=\omega_{0} L_{B}=\frac{.1}{\omega_{0} C_{B}}=\frac{V_{\Phi B}}{I_{a c B}}
\end{aligned}
$$

Equation (4) will be in the same form but of per unit values:

$$
\frac{d V_{s \Phi}}{d t}=K_{s} E_{\Phi} \sin \varphi
$$

Since in per unit system, $V_{s \Phi}=V_{s}$ and $E_{\phi}=E$, later we shall neglect subscript of $\Phi$, and use per unit values of corresponding line to line voltages.

Figure 4(a) shows the block diagram of a STATCOM power frequency model with main controller to regulate the STATCOM terminal voltage and generate the desired phase shift $\varphi$. In order to obtain smooth control, an 'arcsin' function block is inserted. Here $V_{\text {sig }}$ is the input signal for damping the system oscillation from supplementary control. $X_{G}$ is designed for the necessary voltage regulation. However in the real system, the coefficient $K s$ in equation (5) is very large because of the small per unit value of $X s$. In order to keep charging current not to beyond the current limit of GTO thyristors, $\frac{d V_{s}}{d t}$ (which is directly proportional to the charging current of the capacitors) should be limited to certain extent. Therefore the state variable $x$ and the desired phase shift $\varphi$ in Figure 4 have to be very small. For practical simulation, the $V s$ dynamics can be considered as shown in Figure 4(b) with dynamics of $\varphi$ neglected. Here $K s^{\prime}=K \times K s$. Later we shall denote $\mathrm{Ks}^{\prime}$ as $\mathrm{Ks}$. This power frequency model for STATCOM is consistent with the model used in [10] except that the lead-lag block in [10] is replaced by an inertia block here, and the block of $\frac{K}{S}$ in [10] is replaced by the block of $\frac{K_{s} V}{S}$ here with the effect of $V$ on charging dynamics included. The limits of Vsmax and $V_{\text {smin }}$ here are defined same as in [10]. However the model derived here has clear physical meaning and considers VSC charging dynamics more accurately.

\subsection{STATCOM supplementary control model}

The supplementary control of STATCOM is usually designed for damping the power oscillation on transmission lines. The block diagram of STATCOM supplementary control (SC) is similar to the power system stabilizer (PSS) (see Figure 4(c)). Here the input signal of $\mathrm{SC}$ is the real power of a transmission line which experiences strong power oscillation during certain disturbances to be damped by the STATCOM SC. The output signal of $\mathrm{SC}$ is taken as the modulating signal $V_{\text {sig }}$ of STATCOM main control (see Figure 4(b)) similar to the relation of a PSS and an excitation control system.

The parameters of SC can be designed properly via frequency domain technique similar to the PSS design[9].

2.3 Participating_STATCOM system model into power system dynamic analysis programs

The Power System Toolbox (PST) of MATLAB is used for computer software development.

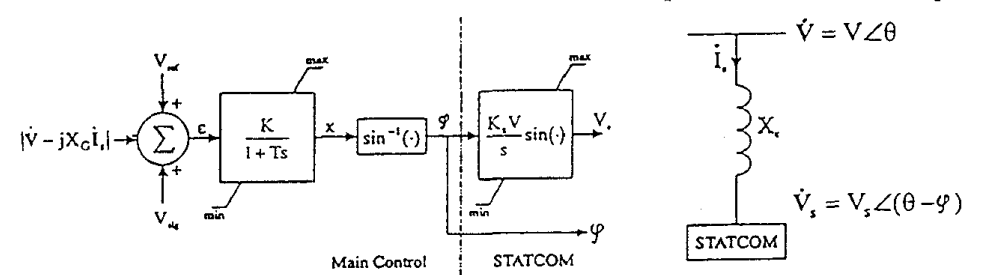

(a)
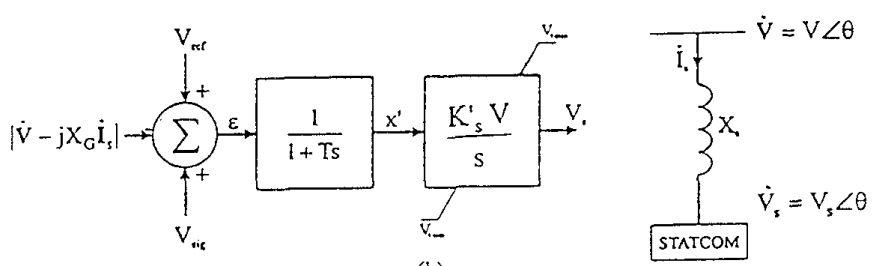

(b)

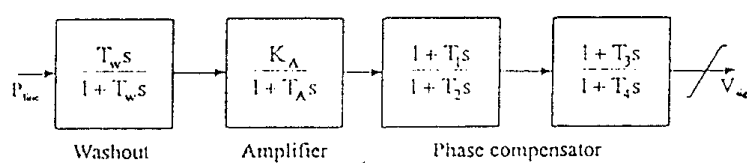

(c)

Figure 4:Hlock diagrams of STATCOM and its main contol 
The advantages of using PST are as follows:

* PST has a modular structure which is flexible to incorporate new element models.

* The matrix calculation is very fast in MATLAB.

* In the new version of PST, sparse matrix technique is utilized.

* PST provides power flow, transient stability, dynamic analysis functions as well as controller design function which is highly desired in power system study.

* The MATLAB files in PST can be edited for developing the STATCOM model.

The main work in participating the STATCOM system model into power system dynamic programs are as follows:

* to add MATLAB files for modeling STATCOM and its $\mathrm{SC}$ to be called in the steps of initialization, network solution and integration,

* to modify the original network solution routine to fit the existence of STATCOM,

* to include the STATCOM model in the transient stability main program

* to include the STATCOM model in the small disturbance stability main program for SC design.

* to avoid numerical stability problems in transient stability analysis program,

* to improve accuracy in forming system matrix via perturbation method [9].

\section{Computer Results}

A two machine power system (see Figure 5) is used for the computer test. Generator 1 is in subtransient model with simplified exciter model. Generator 2 is in classical model with infinite inertia. The load on bus 3 is a constant impedance load. A very short line connects bus 3 and bus 4 with a STATCOM on bus 4 since PST does not allow a load on a STATCOM bus. The real power on line $1-3$ is used as input signal of SC of STATCOM. The base load flow is $\mathrm{P}_{1}=\mathrm{P}_{2}=0.5 \mathrm{P}_{3}=2.5$ p.u. $\left(\mathrm{SB}_{1}=100 \quad \mathrm{MVA}\right)$. The disturbance is a three phase fault on bus 3 at $t=0.10 \mathrm{sec}$. and cleared in three cycles via tripping line 1-3.

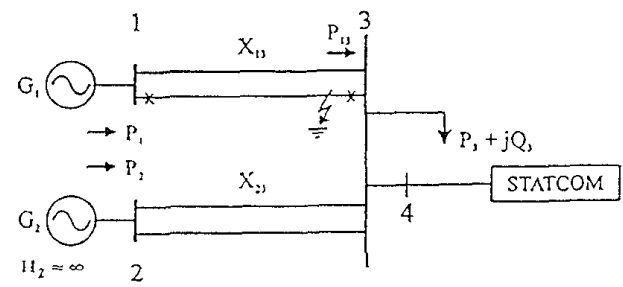

Figure 5: Test system circuit diagram

Figure 6(a) shows the rotor angle of generator 1 w.r.t. generator 2 and Figure $6(\mathrm{~b})$ shows the bus voltages during the transients when there is no STATCOM in the system. The system is unstable under the disturbance.

If a 100MVAr STATCOM is added on bus 4 with the voltage limit set to 1.2 p.u. and the temporary current limit set to 1.25 p.u., the system is stable under the same disturbance which can be seen from Figure 7 where Figure 7 (a) is the relative rotor angle and 7 (b) the bus voltages. However there is severe power oscillation on the transmission line caused by the rotor oscillation between generators 1 and 2. So a damping control is wanted to solve the problem. We can design a PSS on the generator 1 or an SC on the STATCOM. Here we design an SC on the STATCOM since generator 1 may represent an equivalent generator of the sending system.

With properly designed SC parameter, the system dynamic behavior under the same disturbance is greatly improved which can be seen from Figure 8. Figures 8(a) and $8(b)$ are the relative rotor angle and bus voltage transients respectively.

The system transfer limit has also been enhanced when a STATCOM is located on bus 4 . It increases from $\mathrm{P} 1=\mathrm{P} 2=2.2$ p.u. (without the STATCOM) to 2.65 p.u. (with the STATCOM) under the same disturbance described above. The net increase of transient limit is about $20 \%$. Figure 9 shows the transients of rotor angle, bus voltages, and STATCOM current and reactive power absorbed.

It is clear that when the load demand increases, to add a STATCOM is a potential alternative to the construction of a transmission line especially when the right-of-way becomes much more expensive. In the meantime, a STATCOM will not only increase the transfer limit but also improve the system dynamic behavior such as damping power oscillation, providing dynamic reactive power compensation and enhancing system voltage stability etc.

It should be pointed out in order to make full use of STATCOM dynamic characteristics, it is better to operate it at the zero output at the steady state. In practice, an additional control loop with a large time constant should be added in the STATCOM main control to regulate its reference voltage and realize the requirement.

\section{Conclusion}

In this paper, a power frequency model is derived for STATCOM with VSC charging dynamics. The main control for voltage regulation and supplementary control for damping power oscillation are then added. The derived STATCOM system model has been successfully interfaced to the traditional power system transient 


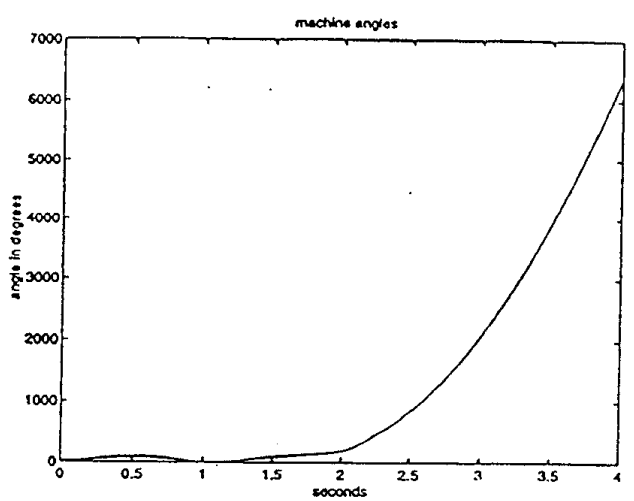

(a)

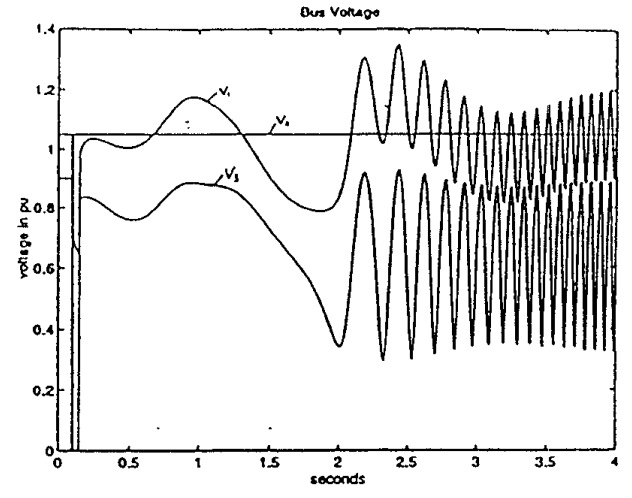

(b)

Figure 6 System transients without STATCOM

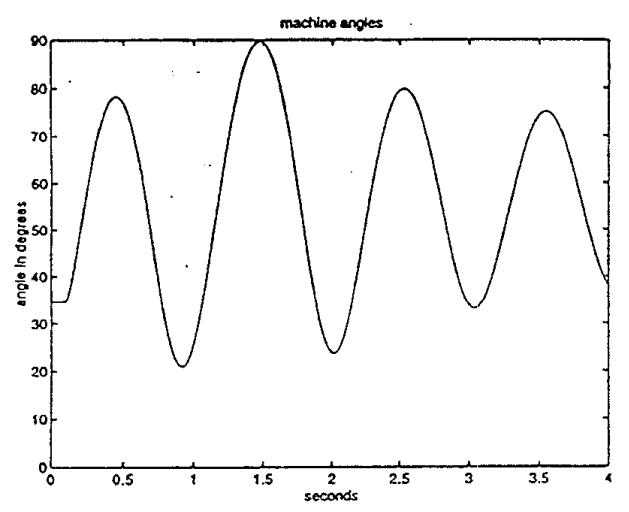

(a)

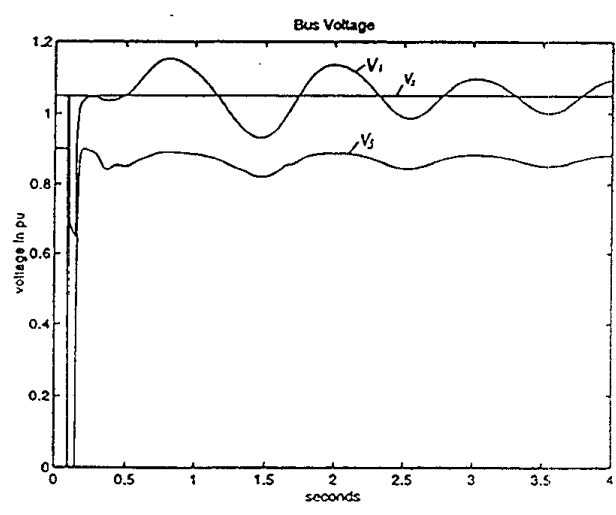

(b)

Figure 7 System transients with STATCOM but without SC

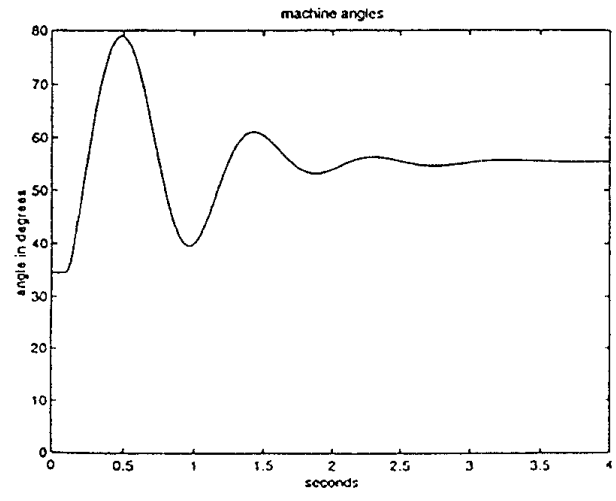

(a)

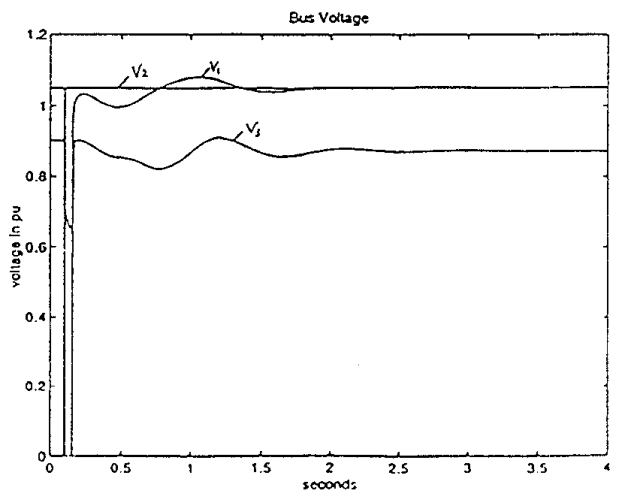

(b)

Figure 8 System transients with STATCOM and its SC 


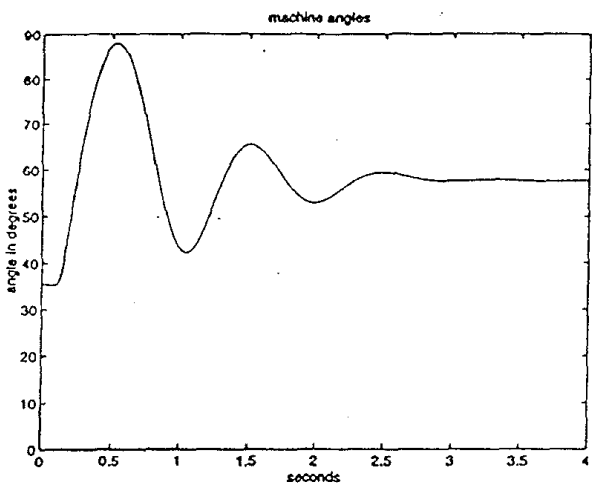

(a)

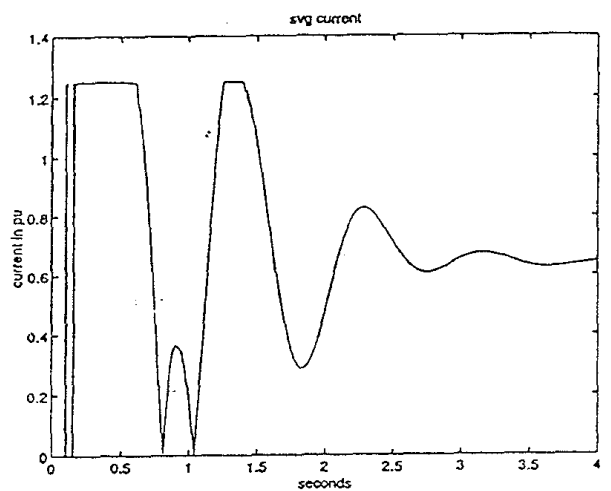

(c)

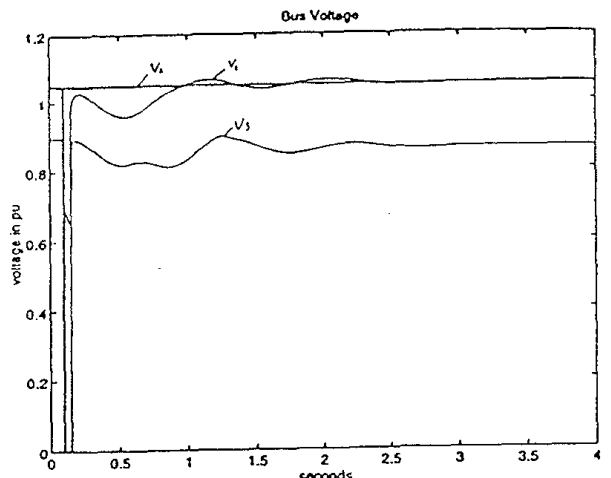

(b)

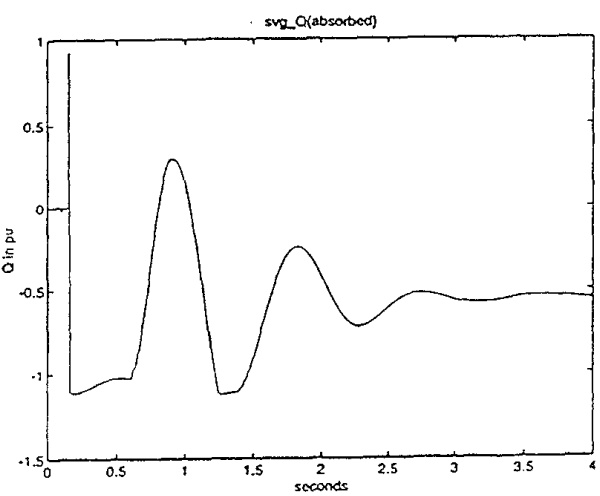

(d)

Figure 9 Plots of the critical stable case

stability program and small disturbance stability program. The latter is used for SC design.

Computer test results show clearly that a STATCOM can substantially improve the global system dynamic behavior and enhance the system transfer limit.

The further research work should be done in applying advanced control theory in the STATCOM controller and its coordination with other system controllers.

\section{Acknowledgment}

The research work is supported by CRCG of the University of Hong Kong to whom sincere acknowledgment is expressed.

\section{References}

1. Edwards, C. W. et al., "Advanced static var generator employing GTO thyristors," IEEE, PES W.M. Paper No. 38WM109-1,1988.

2. Gyugyi, L., et al., "Advanced static var compensator using gate-turn-off thyristors for utility applications," CIGRE paper 23-203, 1990.

3. Schauder, C., et al., "Development of a $\pm 100 \mathrm{MVAr}$ static condenser for voltage control of transmission systems," IEEE Trans. on Power Delivery, Vol. 10, No. 3, 1995.

4. Mori, S., et al., " Development of large static var generator using self-commutated inverters for improving power system stability," IEEE PES W. M. Paper No. 92WM165-1, 1992.

5. IEEE FACTS Application Task Force, "FACTS Applications," Publication of IEEE PES S.M., 1996.

6. Mensies, R., et al., "Advanced static compensation using a multilevel GTO thyristor inverter," IEEE Trans. on Power Delivery, Vol. 10, N0. 2, 1995.

7. Ekanayake, J. B., et al., "A three-level advanced static var compensator," IEEE Trans. on Power Delivery, Vol. 11, No. 1, 1996.

8. Arabi, S., and Kunder, P., "A versatile FACTS device model for powerflow and stability simulation," IEEE PES W. M. Paper No. 96WM258-4PWRS, 1996.

9. Chow, I H., "Power System Toolbox: A set of coordinated m-files for use with MATLAB," Cherry Tree Scientific Software, 1996.

10. Koessler, R., et al., "Feasibility studies for STATCON application in New York State," paper in "FACTS Application', Publication of IEEE PES S.M., 1996. 